\title{
Prevalence of Cattle Lice; Haematopinus tuberculastus and Ticks; Haemaphysalis bispinosa on Cattle at Region Sukkur, Sindh - Pakistan
}

\author{
Hakim Ali Sahito", Tasneem Kousar, Muaz Aslam Mughal, Wali Muhammad Mangrio, \\ Zafar Hussain Shah, Bilawal ul Din Ghumro, Faheem Ahmed Jatoi \\ Department of Zoology, Faculty of Natural Sciences, Shah Abdul Latif University, Khairpur Mir's, Sindh, \\ Pakistan
}

*Corresponding Author: Hakim Ali Sahito, Department of Zoology, Faculty of Natural Sciences, Shah Abdul Latif University, Khairpur Mir's, Sindh, Pakistan

\begin{abstract}
Ectoparasites such as; lice and ticks play an important role in the transmission of certain pathogens which may cause fatal diseases in cattle thus; it may cause heavy economic losses due to their usual habit of blood sucking, which adversely affects the economic production. For this research study the ectoparasites were collected from city Sukkur, Sindh, Pakistan during winter and spring season at fortnightly interval basis from different five farms settled at same side of research area. The overall mean population of cattle lice, $H$. tuberculastus was observed on farm or treatment that indicated with $T=2$ (9.75) followed by $T$ $=3$ (9.62), $T=1$ (7.87), $T=4$ (7.37) and $T=5$ (5.37). Thus; the overall ticks; $H$. bispinosa population was observed in farm number 5 up to (5.40) followed by farm 2 (5.10), farm 4 (4.30), farm 3 (3.41) and the minimum population was observed in farm no. 1 (3.10), respectively. It is concluded that the maximum population of lice was observed in farm no. 2 and minimum at farm no. 5 whereas; the maximum population of ticks was observed at farm no. 5 and minimum at farm no. 1. It is further recommended that the ectoparasites may cause fatal diseases in cattle which may have negative impact on economy such infection in breast may cause reduction in production of milk and cattle may also become week so the antiparasitic; Wormec super $10 \mathrm{ml}$ for cattle should be used to get rid of parasites.
\end{abstract}

Keywords: Ectoparasites, cattle, antiparasitic; Wormec super, cold season.

\section{INTRODUCTION}

Parasites that live on outer surface of the host, either on the skin or the outgrowths of the skin, are called ectoparasites including; lice, ticks, mites that play a vital role in the transmission of specific pathogens (Loomis, 1986). These make serious financial loss to animal industry because of their parasitic habit which negatively influences the economic production (Branscheid and Schroer, 1997). Among ecto-parasites, ticks have been perceived as the infamous danger because of serious disturbance, hypersensitivity and toxicosis. Sometimes, ticks have been accounted for to cause brought down efficiency, mortality (Niyonzema and Kiltz, 1986) and transmit such diseases as babesiosis, theileriosis, anaplasmosis and so forth (Norval et al., 1984). Ticks act as potential vectors as well as repositories of certain irresistible operators e.g. Pasteurella multocida, Brucella abortus and Salmonella typhimurium in man and creatures (Jongejan and Uilenberg, 2004). Other than ticks the lice additionally cause hurt in dairy cattle wellbeing. Lice plagued creatures keep poor physical condition and build up an unthrifty, frail appearance and stained oily hair (Nelson, 1984). Mite free animals have been accounted for to be more beneficial than plagued animals because of expanded rate of weight pick up and more nourish usage (Kettle, 1974). Likewise, lice invasion adds to enormous financial loss because of harm to skin and cover up as light bits and spots took after by optional bacterial disease or scratching conduct and irritation of the skin (Nafstad and Gronstol, 2001).

Ectoparasites are general, every now and again greatly injurious and in most extreme conditions can't be smashed always, as result ectoparasite speak to a chief blockage to the development and misuse of animal asset (Byford et al., 1992) and cause enormous domesticated animals generation misfortune (Soulsby, 1982). In ruminants, ectoparasites make extreme hard luck in economy agriculturists through death of animals. A few examinations on the parasitic diseases in domestic animals including 
sheep, camels, cows, equines were done everywhere throughout the world (Iqbal et al., 2014). Lice influence host straightforwardly by causing irritation and harmed skin, change in behavior that causes self wounding and in a roundabout way exact weight reduction, diminished creation, reduce encourage use, sickliness and exchange pathogen of zoonotic importance (Iqbal et al., 2013). The significant disadvantage related with louse invasion is the premise of lessened cover up and skin quality, which affect leather expert industry along these lines it influence nation economy. Countless parasites infect the healthy animals and cause of yield loss (Iqbal et al., 2014). The purpose of this study was to determine prevalence of ectoparasites as it is the fundamental breading period of the ectoparasites of cattle in major division and city Sukkur, Sindh, Pakistan.

\section{Materials AND Methods}

\subsection{Ectoparasites Collection}

Insects were collected during the months of December, 2016 to April, 2017 on fortnightly interval basis, by the help of gloved hands from 5 different cattle farms, so data was taken as 5 treatments and replicated 5 times, two types of different species of insects were found, one type was mainly found from breast of cattle and other type of species found mostly from dorsal region, neck and tail region of the animal. After collection those were fainted by chloroform and preserved latter on the photographs were taken by the help of $13 \mathrm{mp}$ camera for their proper confirmation or the detailed morphological features.

\subsection{Insect Collection Place}

At the time of collection, the temperature was found very normal or with the cold up to $20 \pm 2^{\circ} \mathrm{C}$ during in winter and spring season of upper Sindh province of Pakistan. There is virtually no rainfall during the year in Sukkur. The average annual temperature mostly ranges up to $27^{\circ} \mathrm{C}$ in Sukkur, about $85 \mathrm{~mm}$ of rain falls annually. Precipitation is the lowest in October, with an average of $0 \mathrm{~mm}$. The greatest amount of precipitation occurs in July, with an average of $34 \mathrm{~mm}$. At an average temperature of $35.7^{\circ} \mathrm{C}$, June is mostly the hottest month of the year. The lowest average temperatures in the year occurred in January, when it was around $15.4^{\circ} \mathrm{C}$ (https://en.climate-data.org).

\subsection{Insect Identification}

Collected specimens were subjected to morpho-metric analysis and their proper confirmation for the occurrence at tropical region of upper Sindh. Prerequisite to analysis the details of ectoparasites along with high resolution photographs were matched with the details of ectoparasites present at (https://en.wikipedia.org) and the ectoparasites were identified as cattle lice; Haematopinus tuberculastus and ticks; Haemaphysalis bispinosa.

\subsection{Statistical Analysis}

Finally, the data was inserted in MS, excel spread sheet and latter on imported for analysis of variance for examination the significant results with the help of SXW software, 8.1, version (USA).

\section{RESUlts}

\subsection{Occurrence of Cattle Lice; H. tuberculastus at Five different Farms of City Sukkur}

The present study was conducted to know the prevalence of different ectoparasites on cattle at city Sukkur, Sindh. Therefore, the five treatments were kept and replicated five times throughout the winter and spring season during, 2016-17 started from the month of December to $1^{\text {st }}$ week of April. During the data collection the magnifying glass was used to locate the nymphs and adult stages of sucking pest throughout whole body of animal from head to tail regions. Subsequently; in each and every farm there were the only most infected animals $(n=5)$ were kept under observation like this; overall 25 animals were kept in all 5 farms as highlighted with treatment wise. For this purpose, the both stages were counted and incorporated accordingly in excel sheet for analysis purpose. The overall mean population of cattle lice, Haematopinus tuberculastus was observed on farm or treatment like; $\mathrm{T}=2(9.75 \pm 0.95 \mathrm{a})$ followed by $\mathrm{T}=3(9.62 \pm 0.95 \mathrm{a}), \mathrm{T}=1(7.87 \pm 0.85 \mathrm{ab}), \mathrm{T}=4$ $(7.37 \pm 0.89 \mathrm{ab})$ and $\mathrm{T}=5(5.37 \pm 1.09 \mathrm{~b})$ with its grouped data of analysis, respectively. The analysis of variance showed the significant difference among the lice attacked on cattle $(\mathrm{DF}=7,4 ; \mathrm{F}=3.29 ; \mathrm{P}=$ 0.02), subjected in under given manner in (Fig. 1). The under given figure further shows that the 
overall data of lice observed during the study period as per mean of every farm / treatment at fortnightly interval basis, the maximum population was observed in cattle farm no. 2 followed by farm $3 ; 1 ; 4$, and with the minimum on farm no. 5 , respectively.

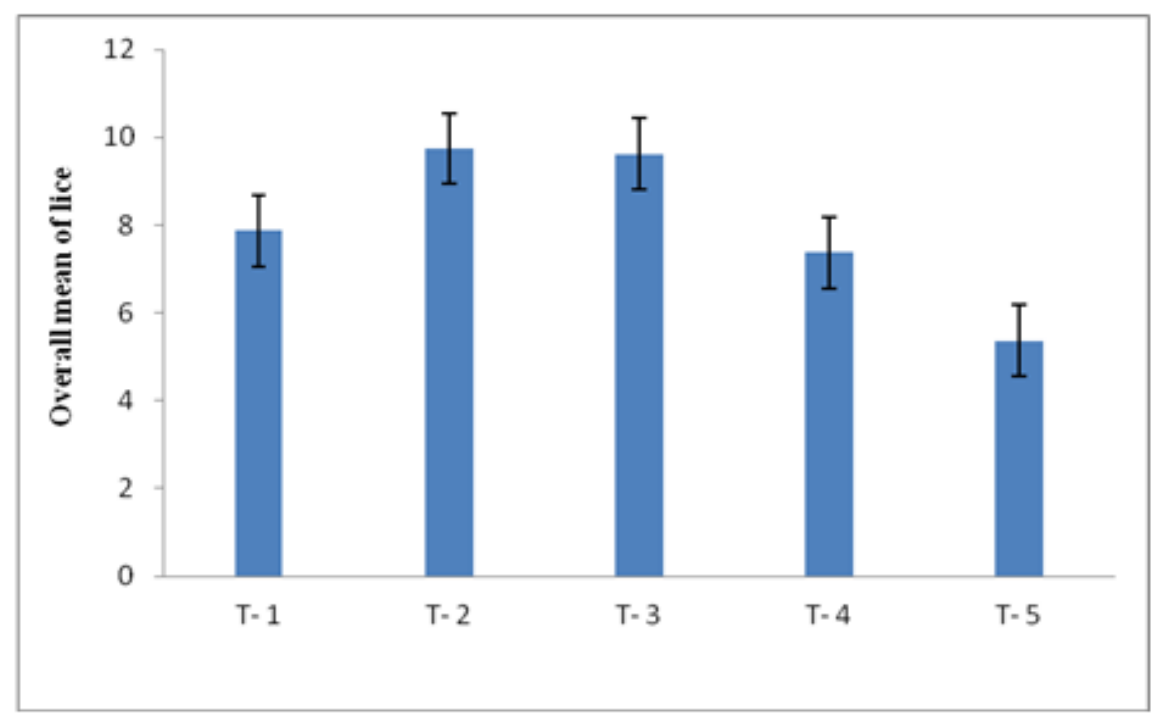

Fig1. Overall mean population of lice on Cattle of region, Sukkur

\subsection{Occurrence of Cattle Ticks; H. bispinosa Population}

The figure no. 2 shows the overall ticks; Haemaphysalis bispinosa population was observed in farm number 5 up to $(5.40 \pm 1.09 \mathrm{a})$ followed by farm no. $2(5.10 \pm 1.08 \mathrm{ab})$, farm no. $4(4.30 \pm 1.32 \mathrm{abc})$, farm no. $3(3.41 \pm 1.23 \mathrm{bc})$ and the minimum in farm no. $1(3.10 \pm 1.68 \mathrm{c})$ with its grouped allotted digits which shows the significant results, respectively. Further, the analysis of variance showed the significant difference among the ticks population observed at different cattle farms located at same vicinity which were attacked on different animals ( $\mathrm{DF}=7,4 ; \mathrm{F}=2.74 ; \mathrm{P}=0.04$ ), respectively described in under given (Fig. 2). During research study some infected animals by ectoparasites were also found vigorous mainly the breast sides were infected which may cause reduction in the production of milk that might have a very negative impact in economy.

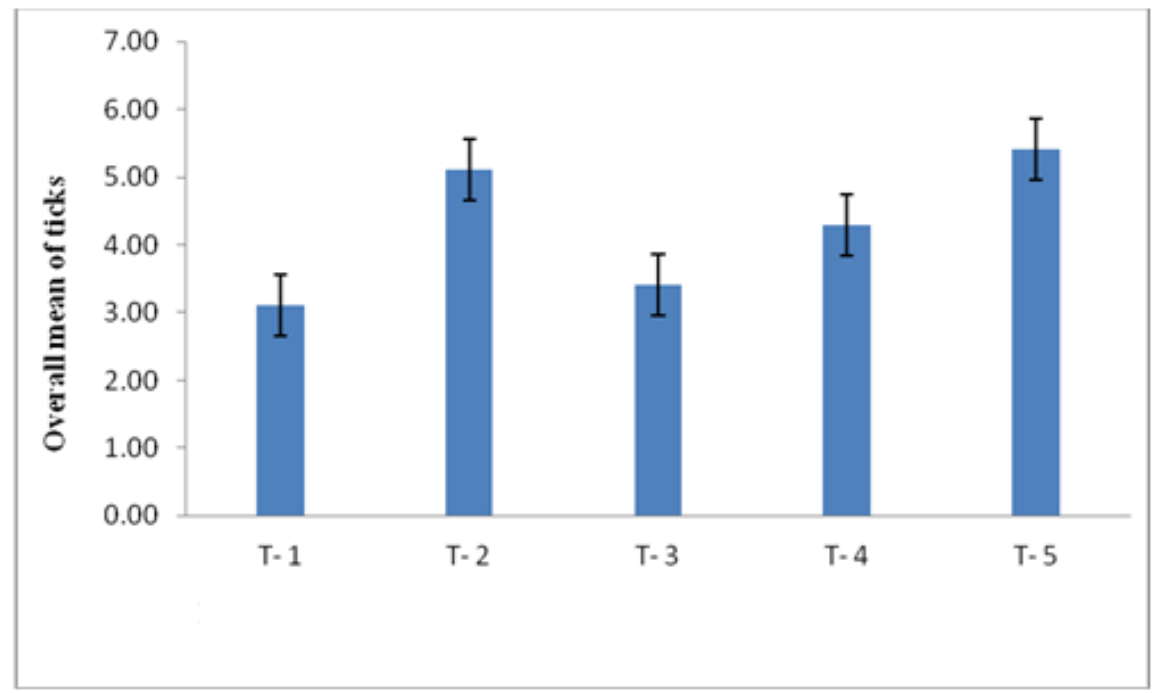

Fig2. Overall mean population of tricks on cattle of region, Sukkur

\section{DISCUSSION}

The outcomes of the present examination demonstrated that high invasion of lice and tick is found on local cattle breeds kept under various production systems. Pervasion of lice was significantly higher from the ticks. This recommends the examination zone is favorable for survival and improvement of various phases of ectoparasites of cattle. The variety in ectoparasites pervasion on cattle of various 
breeds and generation frameworks may be ascribed to contrasts in animal husbandry and control measures against ectoparasites on local cattle breeds, which are generally kept under a broad production system dissimilar to cross breeds. The poor cultivation practices of little holder dairy agriculturists might be a determinant making the animals more inclined to tick pervasion (Sajid et al., 2008). In the present investigation, lice incursion was assemble to elevated than tick and the findings can't help contradicting with past investigations of (Abassi et al., 2016) who carried out their research study on buffalo ticks located at district Khairpur region Sukkur, Sindh - Pakistan. The likely reason would be long period of moist climatic condition in the investigation range. The climatic determinants of the investigation regions are essential in the commonness of ticks in household creatures, humidity and delayed daylight support the survival and propagation of ticks (Sajid et al., 2008; Hassan and AlZubaidi, 2014). Shiferaw and Abebe (2006) announced that tick pervasion of cattle expanded during the wet period of the year, dissimilar to in the dry seasons besides; Solomon et al., (2001) who detailed the prevalence of B. decoloratus where as; Sajid et al., (2008) revealed the power of Hyalomma spp., Amblomma spp., also, Haemaphysalis spp., separately.

The scope of this temperature is higher than the temperature of study region explained temperature is one of imperative hazard factors related with the plenitude and circulation of ectoparasites in cattle. The present assessment entitles for extraordinary ectoparasite control mediation in the district for profitable production of skin and to increase the proficiency of little ruminants. Earlier studies were mostly on commonness of ticks. The reason of higher pervasiveness of tick in domesticated animals types of the investigation region could be because of the atmosphere and geology of the investigation range as the atmosphere factors essentially influence ticks dissemination specifically (Estrada-Pena, 2003). Season assumes enter part in tick spread and it is a set up that pinnacle tick predominance has been accounted for in summer (Rony et al., 2010). From the encompassing piece of the investigation region reports have demonstrated that higher tick commonness in summer (Bekele, 2002)). Delicate and flexible skin of young animals encourages tick and drags out term of connection (Sajid et al., 2008). In male animals higher incidence was additionally announced by (Tasawar et al., 2014). In the present investigation the ticks were for the mostly found from the breast region of cattle and the lice were predominantly found from tail, head and dorsal region of cattle.

\section{CONCLUSION}

During current study it is concluded that ectoparasites may cause fatal diseases in cattle which may have negative impact on economy of the area i.e., infection in breast which may cause reduction in production of milk and cattle may also become week.

\section{RECOMMENDATIONS}

From current study and the results got using different anti parasitic tharapies are being highly recommended for the better cure of repellent these ectoparasites occurred in cattle's. The Wormec Super 10ml was also much suggested from these five different farms were excellent and using this great reduction in parasites, was also observed on other animals located at same farms. In this way sufficient milk can be produced which is very beneficial for the economy of a particular area but after using injection the meat and milk of infected cattle should be avoided to use for three to five days because it may harmful for our health.

\section{ACKNOWLEDGEMENTS}

The authors are highly thankful to owner of the domestic animals of district Sukkur for providing such a facility of visiting their domestic animals at fortnightly interval basis to conduct the research study and Department of Zoology for spacing such a facility of Entomology laboratory at SALU, Khairpur.

\section{REFERENCES}

[1] Abbasi F., H.A. Sahito, I.H.R. Abbasi, T. Kousar and Z.H. Shah. (2016). Occurrence of buffalo ticks at district, Khairpur - Sindh. Pak. J. Entomol., 31(1): 81-89.

[2] Bekele, T. (2002). Study on seasonal dynamics of tick of Ogaden cattle and individual variation in resistance to ticks in Ethiopia. Ethiop. J. Vet. Med., 49: 285-288.

[3] Branscheid, W. and Schroer. (1997). Damage to cattle hides, detection, frequency and economic importance. Fleischwirt schaft, 77: 333-37. 
[4] Byford, R.L., M.E. Craig and B.L. Crosby. (1992). A review of ectoparasites and their effect on cattle production. Journal of Animal Science, 70: 597-602.

[5] Estrada-Pena A., J.J. Osacar, C. Gortazar, C. Calvete and J. Lucientes. (2003). An account of the ticks of the northeastern of Spain (Acarina: Ixodidae). Annales de Parasitologie humaine et comparée, 67: 42-49.

[6] Hassan, R.H., and H.H. Al-Zubaidi. (2014). Cattle and buffaloes tick's infestation in Wasit province districts, Iraq. Kufa. J. Vet. Med. Sci., 5(1): 31-40.

[7] Iqbal, A., M.S. Sajid, M.N. Khan and M.K. Khan. (2013). Frequency distribution of hard ticks (Acari: Ixodidae) infesting bubaline population of district Toba Tek Singh, Punjab, Pakistan. Parasitol. Res., 112(4): 535-541.

[8] Iqbal, A., M.S. Sajid, M.N. Khan and G. Muhammad. (2014). Epizootiology of ectoparasitic fauna infesting selected domestic cattle population of Punjab, Pakistan. Int. J. Agri. Biol., 16: 443-446.

[9] Jongejan, F. and G. Uilenberg. (2004). The Global importance of ticks, Parasitology, 129: 3-14.

[10] Kettle, P.R. (1974). The influence of cattle lice, Damalinia bovis and Linognathus vituli on weight gain in beef animals. New Zealand Vet. J., 22: 10-11.

[11] Loomis, E.C. (1986). Ectoparasites of cattle. Vet. Clin. North America, 2: 299-321.

[12] Nafstad, O. and H. Gronstol. (2001). Variation in the level of grain defect light flecks and spots on cattle hides. Acta. Vet. Scand., 42: 91- 98.

[13] Nelson, W.A. (1984). Effects of nutrition on animals on their ectoparasites. J. Med. Entomol., 21: 621-35.

[14] Niyonzema, A. and H.H. Kiltz. (1986). Control of ticks and tick-borne diseases in Burundi. Australian Center for International Agricultural Research, 17: 16-17.

[15] Norval, R.A.I., B.H. Fivaz, J.A. Lawrence and A.F. Brown. (1984). Epidemiology of tick-borne diseases of cattle in Zimbabwe, Tropical Animal Health and Production, 16: 63-70.

[16] Rony, S.A., M.H.H. Mondal, N. Begum, M.A. Islam and S. Affroze. (2010). Epidemiology of ectoparasitic infestations in cattle at Bhawal Forest area, Gazipur. Bangl. J. Vet. Med., 8: 27-33.

[17] Sajid, S.M., Z. Iqbal, N.M. Khan and G. Muhammad. (2008). Point Prevalence of Hard Ticks (Ixodids) Infesting Domestic Ruminants of Lower Punjab, Pakistan. Int. J. Agri. Biol., 10: 349-51.

[18] Shiferaw, D. and G. Abebe. (2006). Cattle tick dynamics in different agro-ecological zones of Wolayta, southern Ethiopia. Ethiop. Vet. J., 10: 85-99.

[19] Solomon, G., M. Nigist and B. Kassa. (2001). Seasonal variation of tick on calves at Sebeta in Western Shoa Zone. Ethiop. Vet. J., 1: 17-30.

[20] Soulsby, E.J.I. (1982). Helminths, Arthropod and Protozoa of Domesticated Animals, $7^{\text {th }}$ edition. Bailliere, Tindall and Cassell Ltd. pp.136-346, 365-491 and 763-778.

[21] Tasawar, Z., S. Nasim, and M.H. Lashari. (2014). The Prevalence of ixodid ticks on buffaloes at private animal farm Bibipur, Multan. Global. Vet., 12 (2): 154-157.

Citation: H. Sahito et al., "Prevalence of Cattle Lice; Haematopinus tuberculastus and Ticks; Haemaphysalis bispinosa on Cattle at Region Sukkur, Sindh - Pakistan", International Journal of Research Studies in Biosciences (IJRSB), vol. 5, no. 12, pp. 1-5, 2017. http://dx.doi.org/10.20431/2349-0365.0512001

Copyright: (c) 2017 Authors. This is an open-access article distributed under the terms of the Creative Commons Attribution License, which permits unrestricted use, distribution, and reproduction in any medium, nrovided the original author and source are credited. 